\title{
A FORMAÇÃO DO PÓS-GRADUANDO EM QUÍMICA PARA A DOCÊNCIA EM NÍVEL SUPERIOR
}

\section{Agnaldo Arroio}

Departamento de Metodologia do Ensino e Educação Comparada, Faculdade de Educação, Universidade de São Paulo, Av. da Universidade, 308, 05508-040 São Paulo - SP, Brasil

\section{Ubirajara Pereira Rodrigues Filho e Albérico Borges Ferreira da Silva*}

Departamento de Química e Física Molecular, Instituto de Química de São Carlos, Universidade de São Paulo, CP 780, 13560-970

São Carlos - SP, Brasil

Recebido em 19/5/05; aceito em 21/12/05; publicado na web em 22/8/06

\begin{abstract}
THE FORMATION OF CHEMISTRY POST-GRADUATE STUDENTS FOR TEACHING IN HIGHER EDUCATION. The article presents a brief analysis on chemistry post-graduate students' perception on teaching in higher education. This study was done based on the context of students' formation in chemistry post-graduate programs and makes suggestions on how to improve the formation process of post-graduate students in order to decrease the rupture between teaching and research in chemistry post-graduate programs.
\end{abstract}

Keywords: post-graduation; higher education; teaching.

\section{INTRODUÇÃO}

O ensino superior, em geral, é focado na figura do professor e no seu conhecimento. As aulas geralmente são expositivas, leituras de texto e seminários; dificilmente debate-se sobre os procedimentos metodológicos do ensino superior ${ }^{1}$. Nos últimos anos tem-se intensificado a exigência de titulação de Mestrado e Doutorado, visando a melhoria do ensino, o que não garante uma orientação pedagógica para a prática docente. Um outro problema segundo Vasconcelos ${ }^{2}$ seria a falta de um "projeto educacional claramente expresso e definido ao qual todos os seus docentes pudessem se filiar". O processo de construção do projeto de curso seria um espaço de reflexão e/ou o início de uma orientação pedagógica no ensino superior. No entanto, o que ainda estaria orientando a prática docente seriam as suas experiências, enquanto estudantes, inspiradas nos professores que tiveram durante sua formação.

A qualificação de professores para o exercício da docência no Ensino Superior, apesar de não ser uma prioridade estabelecida com rigor no contexto das Políticas Educacionais nos últimos anos, tornase a cada dia mais necessária, uma vez que o professor deve assumir o complexo histórico de constituição da sua área de atuação. Tendo o conhecimento específico de sua área de atuação como instrumento de mediação na relação entre a universidade e a sociedade, o professor necessita possuir um domínio aprofundado deste conhecimento específico para que possa introduzir o aluno no domínio dos métodos da ciência.

Em conjunto ao domínio do conhecimento específico de sua área, é primordial, também, que o professor do ensino superior tenha profunda competência pedagógica, como sendo um requisito importante para trabalhar a formação de seus alunos.

A universidade está enfrentando uma crise, referente ao seu quadro de professores com desempenho no ensino. A referida crise não reside apenas na escassez de massa crítica, mas sobretudo no cumprimento da exigência de qualificação, de titulação e de formação pedagógica necessárias ao exercício da docência.

*e-mail: alberico@iqsc.usp.br
Segundo Pimenta e Anastasiou ${ }^{3}$, nas Instituições de Ensino Superior, em geral, predomina o despreparo e até um certo desconhecimento científico do processo de ensino e de aprendizagem, este mesmo processo do qual os professores são os responsáveis. Notase, hoje, que a admissão de professores, mesmo por critérios de concurso, prática louvável nas universidades públicas, é feita sem levar muito em consideração se o candidato domina ou não o campo de conhecimento pedagógico e as relações entre este com as disciplinas técnico-científicas e outras afins, o que dificulta uma prática pedagógica eficiente. Valoriza-se por demais a produção científica, mesmo em se tratando da contratação de um docente e não de um pesquisador. A maioria dos professores contratados não tem muito domínio do campo pedagógico, o que vem dificultar a prática do ensino com pesquisa. Para Maldaner ${ }^{4}$ este despreparo pedagógico dos professores universitários é fruto de sua própria formação.

O esgotamento do modelo fragmentado de conceber o homem, pelo menos em tese, mesmo que sua utilização ainda balize diversas práticas acadêmicas, e a necessidade de lidar com o humano com base em parâmetros mais amplos, relacionando suas diferentes facetas, trazem para a universidade o desafio de formar profissionais para o nosso tempo e para um novo tempo ${ }^{5}$. Essa realidade exigiria da universidade uma reformulação na política de formação docente.

Para o melhor desempenho pedagógico dos professores, principalmente daqueles que se encontram em estágio probatório, a universidade precisa intensificar programas já existentes de acompanhamento pedagógico que possam oferecer cursos de aperfeiçoamento em didática e metodologia do Ensino Superior, realizar encontros, estabelecer mecanismos de diálogo com os departamentos didáticos, no sentido de tentar superar a antiga dicotomia entre a formação técnico-científica e a formação pedagógica. É necessário que a política de formação pedagógica de professores universitários deva se preocupar, também, com as questões de valores éticos. Entende-se que a competência na docência se encontra indissoluvelmente ligada com os sentimentos de valores, isso porque a exigência da ação pedagógica, relacionada com a formação, sempre implica um dever-fazer e um dever-ser. Assim, os professores inseridos na docência no Ensino Superior precisam estar preparados para trabalhar o conhecimento 
científico com os estudantes em formação, como também para influenciar a conduta destes através da cultura da ética e da cidadania.

\section{DOCÊNCIA}

Atualmente, mais do que nunca, muitos profissionais das mais diferentes áreas buscam a docência no ensino superior como uma forma alternativa e/ou conjugada de inserção no mercado de trabalho. Apesar da legitimidade dessa busca, a vivência com a prática docente no âmbito universitário, ao ocorrer de maneira informal sem a devida apropriação de saberes didático-pedagógicos, pode se revelar difícil e problemática, levando à insatisfação em relação à própria prática pedagógica, receio de avaliações negativas do trabalho realizado (tanto por parte da instituição como do corpo discente), insegurança em relação ao melhor caminho a adotar com uma determinada turma e/ou aluno, sentimento de estar perdido e sozinho sem saber por onde começar, nem tampouco onde chegar (aquela impressão desagradável de que os alunos "não estão nem aî" para os conteúdos da disciplina). Essa experiência negativa tende a suscitar um sentimento de fracasso e desânimo frente às inúmeras situações e desafios vivenciados no cotidiano da sala de aula.

São essas dificuldades e desafios, no entanto, que abrem espaço para que cada vez mais se reconheça que a docência no âmbito universitário é uma profissão que, como tantas outras, pressupõe formação profissional específica. O processo de ensino-aprendizagem, a despeito do nível de formação em que ocorre e longe do que o senso comum imagina, exige por parte do docente a aquisição de um conjunto de competências específicas, que vão muito além do domínio de um saber historicamente acumulado. Saber um determinado conteúdo não é sinônimo de saber ensinar esse mesmo conteúdo. O domínio de um determinado conteúdo, e o do respectivo saber fazer (saberes profissionais diversos), não se transformam automaticamente em saber didático que permita ao professor exercer com competência seu papel no ensino. Isso significa dizer que aqueles que escolhem exercer a atividade docente precisam adquirir, desenvolver e construir esses conhecimentos e habilidades específicas ${ }^{6}$.

A atividade docente é uma atividade de educação. Considerando a educação como prática social, então a atividade docente é também uma prática social. Para exercer a atividade docente é requerido preparo e segundo Benedito apud Pimenta e Anastasiou?, "o professor universitário aprende a sê-lo mediante um processo de socialização em parte intuitiva, autodidata ou (...) seguindo a rotina do 'outros". . Muitas vezes a ausência de uma formação continuada, principalmente no que se refere a ações pedagógicas, leva o professor universitário a rememorar-se de suas experiências no ensino superior; isso, de certa forma, torna-se uma orientação de sua prática. Assim, as experiências que foram vivenciadas enquanto estudante, que são assimiladas nas conversas aleatórias com colegas e/ou que são observadas nos exemplos ou em obras de educadores reconhecidos em sua área de atuação, marcariam ou conduziriam as ações educativas do futuro professor.

Já o ensino superior de Química, teria uma prática docente semelhante aos demais profissionais da educação, pois não faltariam conhecimentos pedagógicos, principalmente pelos docentes egressos de cursos de graduação com licenciatura. O que poderíamos dizer é que muitas práticas educativas seguem uma pedagogia tradicional, centrando o ensino no professor. As aulas limitar-se-iam à exposição do conteúdo pelo professor e ao aluno competiria fazer anotações, estudar para as provas e/ou elaborar os trabalhos de "pesquisa bibliográfica" propostos pelo professor. Este tipo de ensino está baseado em um pressuposto simples e "natural": de que o bom aluno aprende "naturalmente", enquanto o mau aluno é aos poucos ejetado pelo sistema educacional. Ora, isto nada mais é que a aplicação cômoda da Lei de Seleção Natural, postulada por Darwin, na Educação. Reflexo de séculos de mentalidade pouco ou nada democrática, este modelo se reproduz até hoje, com defensores em todos os níveis e classes sociais.

\section{FORMAÇÃO}

A formação de professores constitui-se em um tema de grandes e intensos debates na esfera educacional e no seio das universidades, uma vez que há uma ebulição de diferentes vertentes que buscam verdades em um quadro ainda tão nebuloso quanto incerto. Existe uma significativa preocupação, em termos de investigações, com o preparo do professor para atuar nas séries iniciais do ensino fundamental, opondo-se a raras iniciativas em relação à formação do professor para o ensino superior ${ }^{7}$. Por outro lado, embora o tema oportunize o surgimento de variadas correntes filosóficas, seu conteúdo nos instiga constantemente ao diálogo e à proposição de alternativas inovadoras para a formação das competências que possibilitarão ao professor se tornar um verdadeiro profissional.

De acordo com a Lei Federal 9394, de 20 de dezembro de 1996, que estabelece as diretrizes e bases da Educação Nacional, a formação docente para o nível superior se dá nos cursos de mestrado e doutorado.

\footnotetext{
“Art. 66 - A preparação para o exercício do magistério superior far-se-á em nível de pós-graduação, principalmente em programas de mestrado e doutorado".
}

Ela também evidencia a necessidade da experiência em docência para o exercício do profissional da educação.

\begin{abstract}
“Art. 67 - Parágrafo único - A experiência docente é pré-requisito para o exercício profissional de quaisquer outras funções de magistério nos termos das normas de cada sistema de ensino".
\end{abstract}

Assim, é extremamente relevante para o pós-graduando a oportunidade de vivenciar atividades relacionadas à docência em seu processo de formação, pois, através da reflexão sobre suas experiências, pode romper com o continuísmo tão arraigado em nossos cursos. A maior dificuldade para o recém-formado, no sentido de desenvolver atividades inovadoras, está relacionada ao medo de errar, sendo assim é mais seguro simplesmente reproduzir os modelos tradicionais vivenciados.

As mudanças na educação tornam-se tarefas muito complexas mediante a multiplicidade de interesses. Por outro lado, os programas de pós-graduação visam a formação de pesquisadores, conforme o conceito de mestrado ${ }^{8}$

"Sua finalidade é dar ao aluno uma visão geral para o desenvolvi-
mento de trabalhos científicos e tecnológicos de forma que possa
iniciar-se profissionalmente em uma área de pesquisa"

E, também, pelo de doutorado:

"Deverá propiciar ao aluno maturidade que lhe permita prosseguir como pesquisador independente, após a obtenção do título".

Estes conceitos indicam o compromisso dos programas de pósgraduação na formação de recursos humanos para a pesquisa e não necessariamente para a docência.

Para o estágio de docência da CAPES", disciplinas como "Prática de Ensino" e "Preparação Pedagógica", o Programa de Aperfeiçoamento de Ensino (PAE-USP), etc., apresentam-se como algumas alternativas que vem sendo desenvolvidas por universidades na tentativa de aprimorar a formação do pós-graduando para a docência no ensino superior. 
A preocupação com a formação do pós-graduando para a docência em nível superior é justificável pelo simples fato de que o grau de qualificação, e não apenas a titulação, é essencial para subsidiar a qualidade em qualquer profissão, ainda mais quando estamos nos referindo aos processos educacionais.

\section{PESQUISA}

Por acreditarmos na formação do pós-graduando para a docência em nível superior como sendo um processo, consideramos ser necessário investigar as concepções sobre o tema sob a perspectiva dos alunos de pós-graduação, em formação, com o intuito de colaborar para o aperfeiçoamento deste processo. Trata-se de um estudo preliminar que visa também incentivar os alunos a refletirem sobre o tema, além de obter informações sobre suas concepções a respeito do mesmo. Este tema merece uma atenção especial dos pesquisadores e professores, pois as concepções que estes alunos possuem, que por sua vez foram forjadas em sua educação formal e informal, serão as mesmas que estarão, em geral, representadas em sua atividade docente, pelas quais eles serão os futuros formadores. Estas representações estão arraigadas em suas concepções, que se não forem discutidas, debatidas e refletidas serão perpetuadas durante sua atuação profissional.

Para efetivar este trabalho, a coleta de dados foi feita através de resposta escrita a um questionário (Anexo 1) elaborado para esta finalidade, bem como por anotações durante um workshop sobre "Docência no Ensino Superior", realizado em outubro de 2004.

Os 40 alunos participantes da pesquisa fazem pós-graduação (mestrado e doutorado) nos programas de Pós-Graduação em FísicoQuímica e Química Analítica do Instituto de Química de São Carlos (IQSC), Universidade de São Paulo (USP), e participaram do Programa de Aperfeiçoamento de Ensino (PAE) da USP como bolsistas e voluntários, no segundo semestre de 2004. Dos alunos participantes $70 \%$ são oriundos de cursos de bacharelado e não possuem licenciatura ou outra formação pedagógica, e $90 \%$ realizaram seu curso de graduação em instituições públicas de ensino.

\section{RESULTADOS E DISCUSSÃO}

Os dados que aqui passaremos a analisar foram organizados objetivando uma visão geral das percepções dos participantes. De acordo com a análise dos resultados, $75 \%$ dos alunos participantes declararam que não se sentem preparados para exercer a função docente no ensino superior, ante a $25 \%$ que se declararam preparados para tal função. Dentre os que se declararam não preparados, a maioria apontou a "insegurança", a "falta de preparação" e "ainda não me sinto seguro apesar de algumas experiências" como os principais motivos, ao passo que os que se sentiam preparados apenas declaram estar preparados.

De forma geral nota-se que existe a preocupação com a carreira docente quanto a sua preparação/formação para tal, o que justifica a insegurança declarada na maior parte das respostas. A preocupação com a falta de formação/preparação é algo importante e evidencia uma mudança no que se refere à docência no ensino superior, pois ainda resiste o pensamento de que a atividade docente não requer formação na atividade de ensinar para o nível superior.

A atividade docente requer preparo que não se esgota nos cursos de formação, mesmo tendo uma contribuição muito relevante enquanto conhecimento sistematizado do processo ensino-aprendizagem, e desta forma possibilitando a criação e identificação de uma prática transformadora. Sendo o professor o agente desta prática transformadora, é necessário que possua uma sólida formação também pedagógica, o que certamente lhe assegura maior segurança perante o desenvolvimento da atividade docente.
Quando questionados sobre o programa de pós-graduação, ou seja, se este visa a formação nas três áreas de atuação da Universidade, pesquisa-ensino-extensão, as opiniões se dividem: 55\% acreditam que sim e $45 \%$ que não.

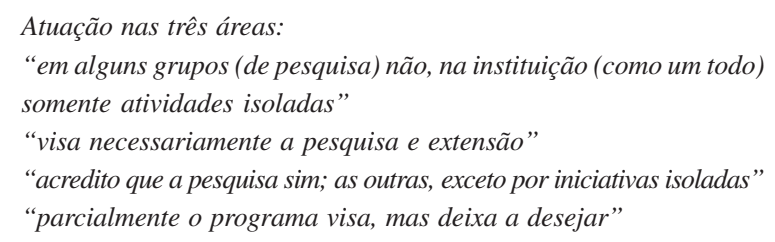

As respostas enfatizam que as atividades de pesquisa e extensão universitária são desenvolvidas não como parte do programa e sim como iniciativas isoladas por professores, alunos e grupos de pesquisa, porém as atividades de ensino não são mencionadas nem como atividades isoladas e muito menos como atividades vinculadas ao programa de pós-graduação.

Diante da falta de preparação e insegurança apontadas anteriormente, e a não integração da pesquisa, do ensino e da extensão, os alunos foram questionados quanto ao que seria necessário para aperfeiçoamento de sua formação docente. Algumas atividades foram sugeridas em suas respostas com uma certa freqüência, por isso agrupamos em algumas categorias de acordo com a Figura 1.

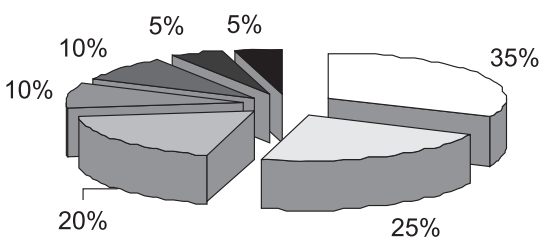

Figura 1. Atividades sugeridas pelos alunos para aperfeiçoamento de sua formação docente. ( $\square$ ) oferecimento de disciplinas didáticas; ( $\square$ ) cursos específicos de educação; (

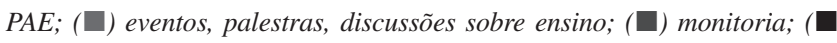
atividade de extensão

A carência de disciplinas relacionadas à área de educação fica evidenciada pelas "disciplinas didáticas" e "cursos específicos", talvez por serem menos privilegiadas dentre a tríade pesquisa, ensino e extensão, assim como a falta de preparação já apontadas anteriormente. Ficam visíveis, de acordo com as colocações dos alunos, as necessidades apontadas em relação à preparação/formação docente.

Muitas das percepções sobre a ação docente se dão de forma empirista, uma vez que suas experiências enquanto aluno irão moldar sua formação e se refletir em sua prática. Essas experiências irão subsidiá-los na formação de modelos bons e/ou maus. Baseando-se em sua experiência como aluno de ensino superior, foi perguntado o que caracterizaria um bom e um mau professor. Com esta pergunta, visou-se identificar quais destas características foram marcantes em sua vida acadêmica, pois estas estariam relacionadas em sua atuação, ou pela repetição das mesmas ou pela tentativa de superá-las.

Características apontadas do bom professor: "ter um bom conhecimento de sua área"; "domina a matéria e sabe transmitir"; "transmite o conhecimento de forma simples"; "ele passa os conceitos"; "passa ao aluno todas as informações"; "torna o conteúdo fácil de ser assimilado"; "tem boa didática"; "comprometido com o ensino"; "possui confiança e aula articulada" e "prende atenção do aluno".

Pelas respostas acima, o bom professor, predominantemente, está estritamente relacionado com o conhecimento através do conteúdo, ou seja, é necessário dominar o conteúdo específico e transmití-lo 
como uma competência docente que garantiria o desempenho dele. Este professor domina o conteúdo e tem o compromisso e a necessidade de transmití-lo aos alunos. Sendo assim, cabe ao aluno estudar e dominar o conteúdo que será transmitido nessa ação docente.

A transmissão do conhecimento acumulado é sim algo importante na ação docente, mas esta ação não se resume somente a uma simples transmissão. A ação docente é muito centrada na figura do professor, não aparecendo registro sobre a aprendizagem do aluno. O processo relatado é de ensino e não ensino-aprendizagem, onde o professor é o agente responsável e a figura central na educação. É necessário que o foco se desloque da figura do professor para o processo, onde neste processo os dois participantes, tanto o professor quanto o aluno, se envolvam em uma relação com o conhecimento que será compartilhado, construído e elaborado por ambos.

A ênfase dada à relação do professor com os conteúdos específicos, nas respostas sobre o bom professor, evidencia que a discussão e a relação entre o ensinar e o aprender tem sido relevada no processo de formação pelos professores universitários, tendo como conseqüência um comprometimento nas relações com os processos de ensino- aprendizagem e desenvolvimento dos alunos e a ausência de uma reflexão sistematizada sobre suas práticas educativas.

Ainda baseados em suas experiências como alunos do ensino superior, foram questionados sobre o que consideram como uma boa aula.

Características apontadas de uma boa aula: "uma aula dada com prazer, descontraída"; "seguro da sua disciplina (conteúdo), inspira confiança”; "quando o professor gosta do que faz"; "quando transmite o conhecimento sem ser exaustivo"; "quando traz novos conhecimentos ou explica de maneira mais prazerosa"; "clara, concisa, e com conteúdo bem dimensionado ocupando o tempo da aula"; "quando o professor passa o seu conhecimento, entretém a classe por dinâmica"; "possui dinâmicas e metodologias diferenciadas, fugindo um pouco das aulas tradicionais para o aluno participar" $e$, "quando o professor apresenta um bom material didático e explica o conteúdo através de exercícios e resolução de problemas".

A boa aula é dependente do "bom professor", pois as questões permanecem ainda centradas na figura do professor detentor do conhecimento, buscando transmitir novos conhecimentos de forma diferenciada da maneira "tradicional". Cabe ao professor propor algo diferenciado, pois a aula é de sua responsabilidade dando a impressão de que o aluno não faz parte da aula. O papel do aluno seria de um cliente que irá receber a aula que será "dada” pelo professor.

Nas respostas sobre uma boa aula, ainda aparece alguma consideração em relação ao aluno quando é mencionado "para o aluno participar". Assim, a figura do aluno aparece como alguém que participa do processo e não somente como alguém que irá receber o resultado do processo que se desenvolve na sala de aula.

As características de um mau professor, segundo as respostas abaixo, dizem respeito à sua falta de compromisso com o ensino.

O mau professor: "não sabe transmitir; às vezes nem domina o conteúdo"; "as informações são passadas superficialmente"; "não passa aos alunos os conceitos básicos"; "ausente, não tem tempo para o aluno"; "possui conhecimento somente para si, não sabe transmití-lo"; "não segue a risca o cronograma de ensino"; "descaso com o ensino" e, "não aceita críticas e faz pouco para mudar".

As características destacadas para um mau professor também aparecem centradas na figura do professor, não fazendo menção ao processo de aprendizagem e estão muito relacionadas com o conteúdo do conhecimento. Quando o professor está aberto para aprender continuamente, deixa de se comportar como dono do saber e não mais se centraliza como figura principal, sendo coadjuvante juntamente com o aluno, como parte de um processo.

De acordo com a legislação vigente, a formação docente para o nível superior dá-se em cursos de pós-graduação; sendo assim, per- guntamos aos alunos qual seria a função de um programa de mestrado e de doutorado.

Função do programa de pós-graduação: "no mestrado fazer pesquisa, é o início de um treino para ser um futuro professor do ensino superior e no doutorado o amadurecimento como pesquisador"; "mestrado para aperfeiçoar na pesquisa e o doutorado para dar ênfase na pesquisa"; "no mestrado preparar uma linha de pesquisa e o doutorado ênfase na pesquisa”; "mestrado é a preparação para o doutorado"; "mestrado é preparação para a formação acadêmica de pesquisa. Doutorado visa ser um pesquisador independente"; "o mestrado forma pesquisadores e não se preocupa com o lado do ensino, até porque isso não é cobrado" $e$, "o mestrado e o doutorado ensinam o aluno a pesquisar".

Temos aí, novamente, apenas uma vertente da tríade pesquisa, ensino e extensão, pois tanto o programa de mestrado quanto o de doutorado visam a formação/preparação para a pesquisa, de acordo com as respostas dos alunos. O ensino e a extensão não são abordados nas respostas referentes à função dos programas de pós-graduação. Logo, a formação docente que é designação dos programas de pós-graduação, conforme a Lei Federal 9394/96, não acontece em tal processo de formação. É interessante registrar que, segundo os dados colhidos, o estágio no PAE, que já foi destacado como uma atividade relevante para a formação do pós-graduando para a docência no ensino superior, não aparece como parte integrante do programa de mestrado e doutorado e sim, como uma atividade isolada para complementar a formação que não ocorre no programa de pós-graduação.

Talvez porque o docente admitido na universidade como professor tenha seu plano de carreira baseado em suas atividades de pesquisa, este seja um dos fatores que supervalorizam a pesquisa e não o ensino. Entretanto, nas respostas mostradas anteriormente, existe uma nítida separação entre a pesquisa e o ensino, por isso foi solicitado aos alunos para comentarem como era a relação entre ensino e pesquisa no programa de pós-graduação que cursavam, e como acreditavam que poderia ser esta relação.

Relação entre ensino e pesquisa: "a relação é satisfatória", "para melhorar a relação, deve-se ter mais disciplinas para a área de educação"; " acredito que essa relação ainda seja subjugada, ensino e pesquisa devem caminhar juntos"; "muito mais pesquisa do que ensino"; "não existe uma relação direta, deveria existir uma parceria entre os programas específicos com os programas voltados para área da educação"; "o ensino não tem uma atenção tão grande quanto a pesquisa, talvez pudessem ser desenvolvidos conjuntamente e equilibradamente"; "relação muito breve, deveria oferecer mais disciplinas obrigatórias voltadas para a educação”; “ a pesquisa é bastante estimulada” $e$, "mais pesquisa que ensino, os professores estão mais preocupados em publicações do que com o ensino”.

Parece-nos assim que, na universidade, as vertentes de pesquisa e ensino são tratadas diferentemente quando deveriam fazer parte de um processo integrado de forma indissociável. Ensino e pesquisa são encarados separadamente como atividades próprias e, às vezes, até polarizadas, mesmo quando as duas atividades estão diretamente relacionadas ao conhecimento e sua produção.

A dicotomia existente está baseada em posturas divergentes assumidas pelo professor enquanto profissional do ensino superior que, de um lado, se apresenta como "inovador", quando faz pesquisa, e de outro, como "conservador", quando leciona. Por que não transpor a inovação para a docência? Por que não romper com essa esquizofrenia?

Até agora estamos analisando algumas características relevantes no processo de preparação/formação do pós-graduando para a docência e temos notado alguns problemas que efetivamente não colaboram para tal formação. Como conseqüência destes problemas podemos ter algumas distorções na formação docente para o ensino superior. Quando questionados sobre o que seria lecionar no 
ensino superior, estas distorções ficam evidenciadas.

Lecionar no ensino superior: "é poder transmitir conhecimento para o crescimento das pessoas"; "é saber repassar a informação de forma simples e eficaz"; "é ensinar aos alunos como construir seu próprio conhecimento"; "direcionar os diversos assuntos, para uma área específica"; "dar aulas em um nível mais elevado"; "tentar desenvolver no aluno a capacidade de busca e relevância das informações frente à uma idéia que se deseja confirmar" $e$, "ter conhecimento mais profundo sobre uma determinada área; ter uma boa didática de forma a facilitar o entendimento do aluno e interesse pela pesquisa".

Lecionar no ensino superior não é simplesmente transmitir o conhecimento acumulado, é uma atividade que vai além dessa transmissão de conteúdos. É uma atividade recíproca que envolve o professor e o aluno através de um processo de ensino-aprendizagem que tem como principal característica a unidade, na qual o professor precisa estar preparado para tanto. Por isso, deve ser mais do que apenas não ser incompetente, deve ser também competente, assumindo que a competência não se restringe a uma matéria ou um objeto, ou seja, ela passa a ser um conjunto de múltiplas determinações e características exigidas do professor e também do aluno, pelo nosso tempo.

Sobre a relação ensino e pesquisa, os alunos ainda foram questionados sobre como traduziriam enquanto docentes em uma IES, sua experiência na pesquisa em sala de aula: "mostraria para os alunos os benefícios que a pesquisa me proporcionou durante toda minha vida acadêmica, ou seja, as habilidades e conhecimento adquiridos"; "relataria as principais dificuldades, os problemas encontrados no método científico, as soluções empregadas; mostraria como um profissional pode atuar na área de pesquisa"; "como forma de aula extra sobre pesquisa, no qual a minha pesquisa seria um exemplo; explicaria como é realizada uma pesquisa na universidade sobre um determinado assunto e, principalmente, qual a importância desse tipo de pesquisa para a sociedade"; "traduziria em exemplos práticos do dia-adia"; "muito proveitosa, pois é na sala de aula que o professor se auto analisa percebendo seus defeitos e qualidades e também buscando sempre a melhora do seu desempenho"; "citando exemplos e estimulando a auto-formação do aluno"; "tentar relacionar a pesquisa científica com o ensino, enfocando em sala de aula os aspectos importantes que possam despertar também o interesse dos alunos pela ciência" e, "uma vez que o resultado de uma pesquisa pode ser reportado na forma de um artigo da literatura e que, em seguida, esta informação serve de base para os conteúdos do livro-texto e também para alguns processos que ocorrem no dia-a-dia profissional de um químico, trabalharia de modo a mostrar estas relações..."

De acordo com as respostas dos alunos, a pesquisa em geral aparece de forma desvinculada do ensino, a relação entre as duas seria apenas como uma demonstração durante as aulas de como se faz pesquisa e não, a incorporação da pesquisa no ensino.

Ensinar não se restringe apenas à transmissão do conhecimento acumulado, assim como a pesquisa é uma busca por respostas aos problemas existentes através da produção de novos conhecimentos. Como o ensino e a pesquisa fazem parte da atividade docente no ensino superior, a sala de aula apresenta-se como um rico potencial a ser explorado pela pesquisa durante as atividades de ensino, ou seja, a pesquisa do ensinar deveria ser realizada por todos os professores dentro da perspectiva da "indissociabilidade".

\section{CONSIDERAÇÕES FINAIS}

Atividades como PAE, cursos de extensão e disciplinas ajudam o aluno a iniciar-se e/ou consolidar-se nessa escolha profissional, à medida em que sua idéia central é oferecer oportunidades e espaços para a reflexão sistemática, o intercâmbio produtivo e a construção coletiva, de modo a assegurar o aprimoramento do saber docente no ensino superior em todas as suas dimensões, respeitando sua especificidade e pluralidade.

Para concluir nossa reflexão referente ao processo de formação profissional do pós-graduando, e em particular à prática docente no ensino superior, apontamos a necessidade de contemplar as demandas sugeridas pelos alunos, principalmente no oferecimento de disciplinas/cursos da área de educação, como espaço para que possam refletir sobre a atividade docente em nível superior, bem como possibilitar a criação de uma identidade docente antes da prática.

A incorporação e sistematização destas atividades nos programas de pós-graduação possibilitam criar elos entre o ensino e a pesquisa por meio de programas de formação de recursos humanos para a pesquisa e a docência. Sendo assim, poder-se-ia criar um espaço de reflexão e de problematização daquilo que tradicionalmente não se debate, que são os procedimentos metodológicos no ensino superior. Considerando uma perspectiva problematizadora e crítica, a vivência docente para o pós-graduando auxilia a busca da superação das contradições e limitações da prática docente no ensino superior, uma vez que as ações educam mais que os discursos.

O estágio no processo de formação do pós-graduando para a docência em nível superior pode estimular se bem direcionado, em uma perspectiva crítico-reflexiva, levando os pós-graduandos a um pensamento autônomo e favorecendo uma dinâmica de auto-formação diferente de uma formação autodidata. O estágio também possibilita interações de troca, compartilhamento dos saberes, re-elaboração e re-significação do conhecimento entre os pares e um profissional sênior na docência. Portanto, o estágio é um espaço que possibilita a criação e recriação de diferentes práticas docentes.

A formação deve ser vista como um processo contínuo, baseado em uma vertente de crescimento, isto é, não se deve entender a formação do pós-graduando como uma somatória de disciplinas científicas com disciplinas pedagógicas e sim, como um amadurecimento ao longo da formação inicial continuando em formação posterior. Valorizando assim a experiência profissional, buscando através de uma diversificação dos modelos e das práticas pedagógicas vigentes com a instituição de novas relações dos professores com os saberes pedagógico e científico. Acreditamos que, desta forma, a postura inovadora que norteia as atividades do pesquisador transcendam para as atividades de ensino, rompendo com esta dicotomia que separa o pesquisador do professor.

Cabe ressaltar, ainda, que um maior diálogo entre orientador e orientando sobre a carreira docente e sua atividade fim poderia em muito contribuir para que as próximas gerações de professores universitários pudessem levar a cabo o desafio que lhes será colocado, ou seja, o de melhorar cada vez mais o ensino superior. Neste espaço democrático de discussão poder-se-ia abordar os desafios de uma profissão que exige de seus profissionais um perfil eclético de professor-orientador-administrador e, mais recentemente, de inovador tecnológico.

Acreditamos na formação como investimento pessoal visando a construção de uma identidade também profissional, que será fruto de um processo contínuo. Portanto, a formação do pós-graduando em Química para a docência no ensino superior não pode ser reduzida simplesmente ao cumprimento de disciplinas, deve-se também promover oportunidades de vivência docente durante este processo, por meio de uma integração destas atividades no programa de formação e não apenas como atividades isoladas.

\section{ANEXO 1}

Questionário usado para a coleta de dados

$\checkmark$ Você se sente preparado para exercer a função docente no ensi- 
no superior?

$\checkmark$ Na sua opinião, o programa de pós-graduação que você realiza visa a formação docente, ou seja, visa uma formação nas três áreas de atuação da Universidade pesquisa-ensino-extensão?

$\checkmark$ O que seria necessário para aperfeiçoar sua formação docente?

$\checkmark$ Baseado na sua experiência como aluno de ensino superior, o que caracteriza um bom professor? E um mal professor? Procure ser objetivo e conciso.

$\checkmark$ Ainda baseando-se em sua experiência como aluno do ensino superior, o que você considera como uma boa aula?

$\checkmark$ Que tipo de atividades poderiam contribuir na sua formação docente para o ensino superior?

$\checkmark$ Na sua opinião, qual é a função de um programa de mestrado? E qual seria a de um programa de doutorado?

$\checkmark$ Como é a relação entre ensino $x$ pesquisa no seu programa de pós-graduação? E como você acredita que poderia ser esta relação?

$\checkmark$ O que é lecionar no ensino superior? $\checkmark$ Como você traduziria, se fosse docente em uma IES, sua experiência na pesquisa em sala de aula?

\section{REFERÊNCIAS}

1. Silva, T. T.; Identidades terminais, Vozes: Petrópolis, 1996

2. Vasconcelos, M. L. M. C.; A formação do professor do ensino superior, $2^{\mathrm{a}}$ ed., Pioneira: São Paulo, 2000.

3. Pimenta, S. G.; Anastasiou, L. das G. C.; Docência no ensino superior, Cortez: São Paulo, 2002.

4. Maldaner, O. A.; Quim. Nova 1999, 22, 289.

5. Batista, S. H. S. da S.; Batista, N. A.; Em Formação docente: Rupturas e Possibilidades; Severino, A. J.; Fazenda, I. C. A., orgs.; Ed. Papirus: São Paulo, 2002.

6. Schön, D. A. Em Os professores e a sua formação; Nóvoa, A., coord. $2^{a}$ ed.; Dom Quixote: Lisboa, 1995.

7. André, M.; Simões, R. H. S.; Carvalho, J. M.; Brzezinki; I.; Educ. Soc. 1999, 68, 301

8. http://www.iqsc.usp.br/iqsc/ensino/posgraduacao/docs/normas, acessada em Maio 2005.

9. Feitosa, J. P. A.; Quim. Nova 2002, 25, 153. 